\title{
Childhood Obesity in the Caribbean: Weighty Challenges \& Opportunities
}

\author{
Fitzroy J. Henry* \\ College of Health Sciences, University of Technology, Jamaica
}

Received: : September19, 2016; Accepted: October12, 2016; Published: October15, 2016

*Corresponding author: Fitzroy J. Henry, College of Health Sciences, University of Technology, 237 Old Hope Road Kingston, Jamaica;

E-mail: Fitzroy.Henry@utech.edu.jm

\begin{abstract}
Childhood obesity rates in the Caribbean are higher than the global average, and are increasing rapidly. The trends reflect economically and culturally driven shifts in dietary practices towards over consumption of energy coupled with shifts towards lower levels of physical activity. Because the causes of these shifts are multifactorial, the preventive intervention actions are not singular and not always clear cut. Although various programs are in place they are far from what is required to make major inroads into halting this obesity epidemic. Bold, creative and sustained policies are required if the region is to strengthen children's learning potential and decrease the risk of nutrition-related chronic diseases later in life. But Caribbean countries are not powerless in developing strategies and activities that can make a substantial impact. This paper outlines some specific actions within various settings that can help stem the increase in childhood obesity in the region.
\end{abstract}

Key words: Childhood obesity; Diet; Physical activity; Policies; Caribbean

\section{The Challenge}

\section{Prevalence}

The obesity tsunami impacting the Caribbean is prominent in childhood. During one decade overweight and obesity rates in pre-school children changed from $6 \%$ to $14 \%$ [1]. This is indeed a weighty challenge because Caribbean children have much higher rates than the global average of 5\% [2-3]. At the older age of 6 to 10 years studies in Jamaica show rates of $17 \%$. Within this narrow age range there was still a significant increase in prevalence as children got older. Significantly higher percentages were also found in girls and in urban areas [4]. The gender difference persisted in early adolescence (11-13 years) with $33 \%$ of girls overweight or obese compared to $27 \%$ among boys across the Caribbean [1]. Even more frightening is the observation that the risk of adult obesity is several times greater in obese children than those non-obese [5-7]. And the spiral continues because children of overweight and obese parents are more likely to be overweight and obese. Parents and the child share the same environment, and parents often feed their children the same fattening foods that they eat and expose them to the same inactive lifestyle. So while physiologic and genetic factors are important [8] it is clear that the critical influences are the obesogenic environment and the adverse behaviors within it [9].

\section{Health risks}

Despite the dramatic fall in under-nutrition in recent decades Caribbean countries still experience significant levels in some regions of these countries. With obesity widespread, some communities show substantial amounts of under-nutrition and also obesity [1]. Obese children are likely to suffer from sleep apnea and those suffering from asthma tend to have worse symptoms than their non-obese counterparts. The major concern, however, is that obese children can develop high blood pressure, and high cholesterol in adults - conditions which increase the risk of heart disease, stroke, osteoarthritis and some cancers [10]. Children at a healthy weight are free of these weight-related conditions and less at risk of developing these diseases in adulthood.

\section{Causes}

Several factors are believed to be contributing to this high prevalence of childhood obesity in the Caribbean and the key influences are outlined. The evidence is clear that breastfeeding protects against childhood overweight and obesity [11,12]. In the Caribbean although the vast majority of mothers breastfeed at birth the rate falls of dramatically by 3 months and at 6 months only $15 \%$ of mothers exclusively breast feed in Jamaica [13]. Between 6 and 11 months among those who breastfeed and introduce complementary foods $85 \%$ do not follow the guidelines [13]. Inappropriate young child feeding practices often lead to overweight infants. Further, much financial savings can result if the recommended child feeding guidelines are followed. The major challenges among older children and adolescents are unhealthy eating and lack of physical activity. These stem from ineffective Caribbean policies related to food supply, food processing, food marketing and transport, among others. Even those children who wish to engage in healthy lifestyle behaviors face weighty challenges from the increasingly obesogenic environment in the region. For example, the World Health Organization (WHO) recommends that children between 5 and 17 years should accumulate at least 60 minutes of moderate to 
vigorous-intensive physical activity daily [10]. In the Caribbean children are more likely to be driven to schools in both urban and rural areas. This may be due to an increasing number of persons having access to motor vehicles. In many countries the school system is so structured that children often go to school far away from home. Children therefore use motorized transport because of the distance and also for security concerns. In addition, children today have fewer opportunities to be involved in recreational sporting activities. The increased emphasis on academics has cut out or drastically reduced sporting programmes in schools. In some systems these academic activities persist after school hours which further limit the amount of time a child has available to participate in sporting events. Further, children today play less active games which are usually restricted to indoor activities like board and computer games. This move to the indoors for children's play may be due both to security concerns and also a lack of space. With more and more children moving to crowded cities and urban areas very many children do not have the space to play. With the availability of dozens of cable television channels, children can sit and watch cartoons and other programs all day, every day. The challenge to meet the WHO recommendations is indeed weighty given these constraining environmental factors.

The national dietary guidelines of Caribbean countries as well as WHO recommend that the intake of sugars should be limited and that energy intake from fats should shift from saturated to unsaturated fats [10]. They further recommend that fruits and vegetables, whole grains and legumes should be increased. In the Caribbean, water is being replaced by sweetened juice drinks and syrups which are very common. There is also a multitude of different candies and sweets, chocolates, cookies, cakes and breakfast cereals available with little limitation on their use. These energy-dense foods are marketed directly to children. They taste more exciting, and children more often choose them. Also heavily marketed to children are fast foods which are relatively cheap, attractive and offer a wide variety of items. With increased competition among the fast food outlets, portion sizes have increased. So children today are more aware of what is available and either ask their parents for them or purchase them on their own. In schools children can buy foods throughout the day from tuck shops and vendors at the gate or vending machines rather than just at meal times. The availability and affordability of these addictive high energy-dense foods make it difficult to adhere to the national dietary guidelines. Despite these weighty challenges, equally weighty opportunities exist to meet them. These are outlined below.

\section{The Opportunities}

The strategies to prevent obesity in the whole population [14] will also have a major impact on childhood obesity. Many of the chronic nutrition-related diseases such as hypertension, heart disease, diabetes and cancers which manifest in adult years have their roots in childhood obesity. And the obesity rates are increasing. This trend can be halted and reversed by instilling positive habits of good nutrition, health and lifestyle through various settings by parents, communities, schools and the general public, among others.

\section{Parents}

Perhaps the most important contribution Caribbean parents can make to control childhood obesity is to provide appropriate nutritional support, including breast feeding, during the first 1000 days of a child's life. Regarding behaviour, parents can provide the most powerful influence on childhood lifestyle practices. This influence is critical in navigating children through an increasingly obesogenic environment. Parents should therefore help and encourage children to evaluate their food preferences and physical activity habits.

\section{Expected Outcome 1}

Wise and healthy lifestyle choices made by children Activities: Send a positive message to children by being a role model. Try to eat right and get physically active regularly.

Ensure that healthy foods are always available in the home and use them for breakfast, school snacks and dinner.

Avoid rewarding good deeds with candy, television watching and video games. Celebrate success with creative and realistic incentives for desirable behaviours which can develop a good self-image.

Gradually influence lifestyle behaviour change by looking for opportunities where the family can have fun together.

Identify physical activities that an individual child loves and seek every opportunity to promote them in place of a sedentary lifestyle habits such as video games and television watching which can also lead to excessive snacking.

\section{Schools}

Obesity, a major risk factor for chronic nutritional diseases, is increasing among school children. Apart from parents, schools provide the longest daily interaction with children and hence a weighty opportunity for positive lifestyle influence.

\section{Expected Outcome 1}

Principles, concepts and skills training about healthy eating and regular physical exercise made mandatory in all levels of school, from pre-school to tertiary institutions. Activities: Create awareness among policy makers, teachers and curriculum planners about healthy diet, physical activities and disease relationships, particularly how these relate to health risks in children.

Design a model curriculum for teaching about food, nutrition, health and healthy eating skills as well as regular physical exercise gradually and sequentially to all students.

Ensure that all children participate in a minimum of 30 minutes of moderate to vigorous physical activity during the school day.

\section{Expected Outcome 2}

Nutrition education and physical activity incorporated into a healthy lifestyle programme in schools. Activities: 
Conduct nutritional assessment of schoolchildren to (1) determine the trends in nutritional status and (2) provide information for counseling.

Plan and implement healthy lifestyle programmes to enable children to make informed decisions.

\section{Expected Outcome 3}

Policies to support healthy diet and lifestyle choices developed by school management. Activities: Evaluate current foods offered at the school cafeteria and modify them in keeping with national dietary recommendations, whilst also discouraging the excessive use of salt, sugar- and fat-containing foods

Develop incentives for students to make healthy dietary choices.

Introduce competitions as incentives to promote physical activity for all categories of students, not only the athletically gifted.

Involve school health services and parents in childhood obesity prevention efforts

\section{Communities}

Community action is critical to reinforce actions in schools to control obesity. The community has formal institutions such as church, youth clubs and community centres from which individual and group initiatives can be spawned to improve dietary and other lifestyle habits.

\section{Expected Outcome 1}

Community-oriented nutrition and lifestyle programmes developed. Activities: Involve community development workers in health, sports and other sectors to promote healthy eating habits.

Involve community action groups in designing and implementing programmes for the prevention of obesity particularly in high-risk low-income groups.

Identify and train resource persons in the community to obtain skills in food preparation and healthy eating.

Identify or provide safe and inexpensive exercise facilities in communities. For example: after school use of school facilities; use of school as a community centre to promote physical activity.

Promote daily physical exercise for healthy living through community organizations (e.g. youth clubs, service clubs) and to avoid weight gain, for persons who are not physically active.

Encourage the initiation of community projects that will increase availability and affordability of fruits, vegetables, legumes and ground provisions for the community.

\section{General Public}

Childhood obesity must be tackled from within families and schools, but reinforcement is also critical from the general public. Many Caribbean countries have developed national dietary guidelines which are meant to reduce obesity and the devastating diseases such as diabetes, high blood pressure, heart attack, stroke and cancer. The challenge is to utilize these guidelines to improve the chances of a healthier life.

\section{Expected Outcome 1}

The public is aware of, and convinced of, the need to develop and maintain healthy lifestyle habits. Activities: Launch and maintain massive public education campaigns to inform the public about the dietary guidelines using the mass media - radio, television, newspaper, posters and leaflets. This should be done on the basis of audience segmentation.

Provide support, incentives, and introduce competitions, which challenge the public to seek and obtain information on healthy eating and physical activity.

\section{Expected Outcome 2}

The public is provided with consistent educational messages and dietary recommendations. Activities: Develop applications for computers and smart phones that can provide the public with information on food, nutrition, exercise regimes and health.

Develop and disseminate scientific-based nutrition and lifestyle education materials to all audiences.

Review and monitor educational messages that reach the public to ensure consistency and conformity to the national guidelines.

\section{Conclusion}

The rapid rise in childhood obesity in the Caribbean will not be halted with feeble and ineffective policies and programs. To harness the superior learning capacity of non-obese children and to decrease the risk of nutrition-related chronic diseases countries of the Caribbean must give priority attention to addressing these weighty childhood challenges. Clearly, the need is for major investments in the protective factors at the family, school and community level to attain substantial advances in healthy lifestyles in childhood. It is not expected that every country will implement all of these activities outlined here but the aim was to present options that policy makers can implement based on political, practical and financial feasibility.

To address these weighty challenges Caribbean countries need to implement bold and appropriate policies which can shape environments that will enable children to access healthy, affordable meals and also safe, attractive settings for increased physical activity. A multi-sectoral, multi-level, evidence-driven approach is therefore essential to halt childhood obesity in the region.

\section{References}

1. Caribbean Food and Nutrition Institute. The Contribution of CFNI to Caribbean Development 2001 - 2010. CFNI/PAHO, 2011.

2. de Onis $\mathbf{M}$ and Blössner $\mathrm{M}$. Prevalence and trends of overweight among preschool children in developing countries. Am J Clin Nutr. 2000;72(4):1032-9.

3. Olds T, Maher C, Zumin S, et al. Evidence that the prevalence of childhood overweight is plateauing: data from nine countries. Int J PediatrObes. 2011;6(5-6):342-60.doi: 10.3109/17477166.2011.605895. 
4. Blake-Scarlet BE. Younger N. McKenzie C A, et al. Prevalence of overweight and obesity among children six to ten years of age in the North-East Health Region of Jamaica. West Indian Med J. 2013;62(3):171-6.

5. Serdula M.K, Ivery D., Coates RJ, Freedman DS, Williamson DF, Byers T. (1993). Do obese children become obese adults? A review of the literature. Prev Med. 1993;22(2):167-77.

6. Freedman DS, Dietz WH, Srinivasan SR, Berenson GS. (2009). Risk factors and adult body mass index among overweight children: the Bogalusa Heart Study. Pediatrics. 2009;123(3):750-7. doi: 10.1542/ peds.2008-1284.

7. Biro FM, Wien M. Childhood obesity and adult morbidities. Am J Clin Nutr. 2010 ;91(5):1499S-1505S. doi: 10.3945/ajcn.2010.28701B.

8. Walley AJ, Asher JE, Froguel .The genetic contribution to nonsyndromic human obesity. Nat Rev Genet. 2009;10(7):431-42. doi: $10.1038 /$ rrg2594.

9. Hu F.Genetic predictors of obesity. In: Hu F, ed. Obesity Epidemiology.
New York City: Oxford University Press, 2008; 437-460.

10.WHO . Obesity: preventing and managing the global epidemic, WHO Technical report series no. 894 (Geneva: World Health Organization, 2000

11. Arenz S, Ruckerl R, Koletzko B, von Kries R. Breast-feeding and childhood obesity - a systematic review. Int J Obes Relat Metab Disord. 2004;28(10):1247-56.

12. Owen CG, Martin RM, Whincup PH(2005).Effect of infant feeding on the risk of obesity across the life course: a quantitative review of published evidence. Pediatrics 2005; 115:1367-1377.

13. Multiple Indicator Cluster Survey (MICS). Statistical Institute of Jamaica \&United Nations Children's Fund. UNICEF, 2005.

14. Henry FJ. Obesity prevention: The key to non-communicable disease control. West Indian Med J. 2011;60(4):446-51. 